Article

\title{
Pro-Angiogenic and Osteogenic Effects of Adipose Tissue-Derived Pericytes Synergistically Enhanced by Nel-like Protein-1
}

\author{
Hyun-Ju An ${ }^{1,+} \mathbb{D}$, Kyung Rae Ko ${ }^{2,+} \mathbb{D}$, Minjung Baek ${ }^{1}$, Yoonhui Jeong ${ }^{1}$, Hyeon Hae Lee ${ }^{1}$, Hyungkyung Kim ${ }^{3} \mathbb{D}$, \\ Do Kyung Kim ${ }^{4}$, So-Young Lee ${ }^{5}$ and Soonchul Lee ${ }^{1, *}$
}

1 Department of Orthopaedic Surgery, CHA Bundang Medical Center, CHA University School of Medicine, 59 Yatap-Ro, Seongnam-si 13496, Gyeonggi-do, Korea; yks486ahj@naver.com (H.-J.A.); eclsa79@gmail.com (M.B.); jeongyunhui92@gmail.com (Y.J.); aotcnlsl@gmail.com (H.H.L.)

2 Department of Orthopaedic Surgery, Samsung Medical Center, Sungkyunkwan University School of Medicine, 81 Irwon-Ro, Gangnam-gu, Seoul 06351, Korea; krmd.ko@gmail.com

3 Department of Pathology, Kyung Hee University Hospital at Gangdong, Kyung Hee University, College of Medicine, 892 Dongnam-Ro, Gangdong-gu, Seoul 05278, Korea; hyungkyungjkim@gmail.com

4 CHA Graduate School of Medicine, 120 Hyeryong-Ro, Pocheon-si 11160, Gyeonggi-do, Korea; dokim1018@naver.com

5 Department of Internal Medicine, CHA Bundang Medical Center, CHA University School of Medicine, 59 Yatap-Ro, Seongnam-si 13496, Gyeonggi-do, Korea; ysy0119@cha.ac.kr

* Correspondence: 1sceline78@gmail.com; Tel.: +82-317-805-289; Fax: +82-317-083-578

+ These authors contributed equally.

check for updates

Citation: An, H.-J.; Ko, K.R.; Baek, M.; Jeong, Y.; Lee, H.H.; Kim, H.; Kim, D.K.; Lee, S.-Y.; Lee, S.

Pro-Angiogenic and Osteogenic Effects of Adipose Tissue-Derived Pericytes Synergistically Enhanced by Nel-like Protein-1. Cells 2021, 10, 2244. https://doi.org/10.3390/

cells10092244

Academic Editor: Georg Breier

Received: 2 July 2021

Accepted: 24 August 2021

Published: 30 August 2021

Publisher's Note: MDPI stays neutral with regard to jurisdictional claims in published maps and institutional affiliations.

\section{Copyright: (c) 2021 by the authors.} Licensee MDPI, Basel, Switzerland. This article is an open access article distributed under the terms and conditions of the Creative Commons Attribution (CC BY) license (https:// creativecommons.org/licenses/by/ $4.0 /)$.

\begin{abstract}
An important objective of vascularized tissue regeneration is to develop agents for osteonecrosis. We aimed to identify the pro-angiogenic and osteogenic efficacy of adipose tissue-derived (AD) pericytes combined with Nel-like protein-1 (NELL-1) to investigate the therapeutic effects on osteonecrosis. Tube formation and cell migration were assessed to determine the pro-angiogenic efficacy. Vessel formation was evaluated in vivo using the chorioallantoic membrane assay. A mouse model with a $2.5 \mathrm{~mm}$ necrotic bone fragment in the femoral shaft was used as a substitute for osteonecrosis in humans. Bone formation was assessed radiographically (plain radiographs, three-dimensional images, and quantitative analyses), and histomorphometric analyses were performed. To identify factors related to the effects of NELL-1, analysis using microarrays, qRT-PCR, and Western blotting was performed. The results for pro-angiogenic efficacy evaluation identified synergistic effects of pericytes and NELL-1 on tube formation, cell migration, and vessel formation. For osteogenic efficacy analysis, the mouse model for osteonecrosis was treated in combination with pericytes and NELL-1, and the results showed maximum bone formation using radiographic images and quantitative analyses, compared with other treatment groups and showed robust bone and vessel formation using histomorphometric analysis. We identified an association between FGF2 and the effects of NELL-1 using array-based analysis. Thus, combinatorial therapy using AD pericytes and NELL-1 may have potential as a novel treatment for osteonecrosis.
\end{abstract}

Keywords: pericytes; Nel-like protein-1; angiogenesis; bone regeneration; bone formation; osteonecrosis

\section{Introduction}

Angiogenesis is a vital process for normal tissue development and supports skeletal growth. It is also associated with a variety of pathological conditions [1,2]. Pathological angiogenesis is a hallmark of various ischemic conditions [3]. Therefore, restoring vascular homeostasis and therapeutic angiogenesis have great potential for the treatment of ischemic conditions. The pursuit of a safe and efficacious approach to restoring angiogenesis is a field of ongoing research [2].

Avascular necrosis is defined as the cellular death of bone caused by interruption of normal blood flow. It most frequently affects the femoral head (i.e., osteonecrosis of 
the femoral head, ONFH). The affected limb becomes progressively more painful and debilitated with progressive collapse of subchondral bone and development of osteoarthritis. Total hip arthroplasty is regarded as a reliable surgical procedure in the treatment of advanced ONFH, but the lifetime risk of revision is a concern, especially in young patients [4]. Core decompression is one of the most commonly performed surgical procedures for early-stage ONFH. However, ideal indications of core decompression have been debated [5], and recent studies have focused on its use combined with regenerative techniques rather than its use alone in terms of improved results [6]. To overcome the limitations of current treatments, it is highly desirable to develop agents to enhance angiogenesis and bone formation.

As a regenerative therapeutic option in the field of orthopedic surgery, significant effects of human perivascular stem cells combined with Nel-like protein-1 (NELL-1) in angiogenesis and osteogenesis have been demonstrated using a mouse model of ectopic bone formation and [7] a rat model of osteoporosis [8]. Considering the need for novel therapeutic options in ONFH, we focused on their synergistic effects shown in the previous animal models $[7,8]$.

Perivascular stem cells are found in all vascularized tissue; therefore, they are abundant and easily harvestable [9]. As they can be used after sorting, bypassing culture expansion, the extra time and risks related to ex vivo expansion can be eliminated [7]. Perivascular stem cells consist of (1) pericytes, which line micro-vessels, and (2) adventitial cells found in the tunica adventitia of large arteries and veins [9-12]. Pericytes have critical roles in the regulation of endothelial cell function and angiogenesis [10,12-14]. During angiogenesis, pericytes participate in recruitment, extracellular matrix modulation, paracrine signaling, and direct interactions with endothelial cells [15]. Study results indicate that pericytes participate through direct cell contact and communication. Their main functions include angiogenesis stimulation, regulation of blood vessel diameter [15], and maintenance of vascular permeability and integrity [16]. Because of their effects on endothelial cells, the study of pericytes is a research area of increasing interest that includes evaluation as potential targets of pro-angiogenic therapies [17]. While their presence in microcirculation has long been documented, their functional roles and importance have been largely under-investigated.

As mentioned above, NELL-1 is a potential additive to enhance angiogenesis and bone formation $[7,8]$. It was first identified as an osteoinductive protein via its overexpression in cranial sutures [18]. It has robust bone formation effects in the axial skeleton and the extremities in in vivo settings [19-24]. Further, NELL-1 can stimulate the proliferation of perivascular stem cells [25] and has anti-osteoclastic effects [26].

On this background, we conducted a study on the synergistic effects of pericytes combined with NELL-1. Our examination of the potential for this combination as a novel therapeutic agent for osteonecrosis included the use of a mouse model with a necrotic bone fragment.

\section{Methods}

2.1. NELL-1 and Human Stromal Vascular Fraction (HSVF) Isolation from Human Adipose Tissue and Purification of Human Pericytes from HSVF

The NELL-1 was kindly provided by Professors Kang Ting, Chia Soo, and Xinli Zhang (UCLA, USA). Human adipose tissue was obtained from 8 patients who underwent total knee arthroplasty due to degenerative osteoarthritis (Table 1). The adipose tissue samples were stored $\left(4^{\circ} \mathrm{C}\right)$ until they were processed. All samples were processed within $48 \mathrm{~h}$ after collection. Human stromal vascular fraction (hSVF) was prepared by digesting the adipose tissue using collagenase digestion, as previously described [8]. The adipose tissue was briefly washed in an equal volume of phosphate-buffered saline (PBS). Collagenase digestion was performed using Dulbecco's Modified Eagle's Medium (DMEM; SigmaAldrich, St. Louis, MO, USA) containing 3.5\% bovine serum albumin (Sigma-Aldrich) and $1 \mathrm{mg} / \mathrm{mL}$ collagenase type II for $70 \mathrm{~min}$ under agitation at $37^{\circ} \mathrm{C}$. The filtered solution was centrifuged to separate and exclude adipocytes. The processed hSVF was suspended in 
red cell lysis buffer (155 mM NH $4 \mathrm{Cl}, 10 \mathrm{mM} \mathrm{KHCO}_{3}$, and $0.1 \mathrm{mM}$ EDTA) and incubated for $10 \mathrm{~min}$ at room temperature. The hSVF filtrate was immediately processed for human pericyte purification.

Table 1. Human adipose tissue samples used in the study.

\begin{tabular}{|c|c|c|c|c|c|c|}
\hline Samples ${ }^{a}$ & Sex/Age & $\begin{array}{l}\text { Past Medical } \\
\text { History }\end{array}$ & SVF Yield & $\begin{array}{c}\text { SVF } \\
\text { Viability }\end{array}$ & $\begin{array}{c}\text { Ratio of } \\
\text { Pericytes in } \\
\text { SVF }\end{array}$ & $\begin{array}{l}\text { Pericytes } \\
\text { Yield }\end{array}$ \\
\hline 1 & $\mathrm{M} / 75$ & Hypertension & $22.4 \times 10^{6}$ & $90.3 \%$ & 0.27 & $5.46 \times 10^{6}$ \\
\hline 2 & $\mathrm{M} / 68$ & Diabetes mellitus & $25.1 \times 10^{6}$ & $85.2 \%$ & 0.22 & $4.70 \times 10^{6}$ \\
\hline 3 & $\mathrm{~F} / 73$ & None & $19.0 \times 10^{6}$ & $88.2 \%$ & 0.24 & $4.02 \times 10^{6}$ \\
\hline 4 & $\mathrm{~F} / 82$ & $\begin{array}{l}\text { Hypercholesterolemia, } \\
\text { Diabetes mellitus }\end{array}$ & $31.4 \times 10^{6}$ & $78.3 \%$ & 0.31 & $7.62 \times 10^{6}$ \\
\hline 5 & $\mathrm{~F} / 66$ & None & $29.2 \times 10^{6}$ & $79.2 \%$ & 0.22 & $5.09 \times 10^{6}$ \\
\hline 6 & $\mathrm{~F} / 72$ & None & $22.3 \times 10^{6}$ & $92.4 \%$ & 0.19 & $3.91 \times 10^{6}$ \\
\hline 7 & $\mathrm{~F} / 65$ & $\begin{array}{l}\text { Hypertension, HBV } \\
\text { carrier }\end{array}$ & $15.1 \times 10^{6}$ & $83.7 \%$ & 0.29 & $3.67 \times 10^{6}$ \\
\hline 8 & $\mathrm{~F} / 70$ & Hypertension & $17.6 \times 10^{6}$ & $87.9 \%$ & 0.23 & $3.56 \times 10^{6}$ \\
\hline
\end{tabular}

A fluorescence-activated cell sorter (FACS) was used to purify human pericytes from isolated hSVF, as previously described $[11,27]$. The isolated hSVF was centrifuged, and the resulting pellet was incubated $\left(4^{\circ} \mathrm{C}\right.$ for $15 \mathrm{~min}$ in the dark) with conjugated 1:100 dilutant antibodies (anti-CD34-phycoerythrin (Dako), anti-CD45-allophycocyanin (Santa Cruz Biotechnology, Inc., Dallas, TX, USA), and anti-CD146-fluorescein isothiocyanate (AbD Serotec)). The hSVF pellet was then resuspended in PBS and 4', 6-diamidino-2phenylindole (Invitrogen, Carlsbad, CA, USA) and was filtered through a $70 \mu \mathrm{m}$ cell filter for removal of nonviable cells. The solution was processed on a FACS Aria cell sorter (BD Biosciences, San Jose, CA, USA) to isolate populations of cells that constituted human pluripotent stem cells based on cell surface markers: pericytes (CD146+, CD34-, CD45-).

\subsection{Osteogenic and Adipogenic Differentiation of Human Pericytes}

The human pericytes were cultured separately in the PBS control and NELL-1 solutions to determine the differentiation potential of human pericytes and to test the biologic activity of NELL-1 protein during osteogenesis and adipogenesis. Osteogenic differentiation of the pericytes occurred over a period of $15 \mathrm{~d}$. The cells were added to 24-well plates $\left(3 \times 10^{4}\right.$ cells / well density) with DMEM $+10 \%$ fetal bovine serum (FBS). Within $24 \mathrm{~h}$, osteogenic differentiation of the cells was induced in the PBS control and NELL-1 $(800 \mathrm{ng} / \mathrm{mL})$ treatments using osteogenic differentiation medium (DMEM + 10\% FBS + $50 \mu \mathrm{g} / \mathrm{mL}$ ascorbic acid, and $3 \mathrm{mM} \beta$-glycerophosphate). The medium was changed every $3 \mathrm{~d}$. Alizarin Red staining was used to assess osteogenic differentiation.

For adipogenic differentiation, human pericytes were added to 24 -well plates $\left(5 \times 10^{4}\right.$ cells/well density) with DMEM $+10 \%$ FBS. In $24 \mathrm{~h}$, cells were induced to adipogenic differentiation in the PBS control and NELL-1 $(800 \mathrm{ng} / \mathrm{mL})$ treatments using adipogenic differentiation medium (Human MesenCult ${ }^{\mathrm{TM}}$ Adipogenic Differentiation Medium; STEMCELL TECHNOLOGIES, Catalog \#05412). Adipogenic differentiation was performed over $12 \mathrm{~d}$. The medium was changed every $3 \mathrm{~d}$. Adipogenic differentiation was assessed at $12 \mathrm{~d}$ using Oil Red O staining.

\subsection{Endothelial Cell Culture}

Human umbilical vein endothelial cells (HUVECs) were purchased from Lonza and cultured in an endothelial growth medium (Lonza, Basel, Switzerland). The cells were used between passages 4 and 7 [28]. 


\subsection{Viability Test}

HUVECSs were seeded in 96-well plates $\left(4 \times 10^{4}\right.$ cells / well) and treated with pericyte and NELL-1. A total of 2000 pericytes were added to $100 \mu \mathrm{L}$ DMEM in each well of two 96well plates. The cells were incubated in DMEM with $800 \mathrm{ng} / \mathrm{mL}$ NELL-1 for $72 \mathrm{~h}$. Control cells were incubated with only DMEM. A water-soluble tetrazolium salt (WST) assay (Cell Counting Kit-8; Dojindo, Kumamoto, Japan) was used to measure cell proliferation. Then, WST $(10 \mu \mathrm{L})$ was added to each well and the cultures were incubated for an additional $2 \mathrm{~h}$ at $5 \% \mathrm{CO}_{2}$ and $37^{\circ} \mathrm{C}$ before evaluation using spectrophotometry. Conversion of WST to formazan was measured at $450 \mathrm{~nm}$. The results were normalized and were presented as a percentage of the viable cells in the control group $[29,30]$.

\subsection{Tube Formation Assay}

A capillary tube formation assay (Matrigel, Corning, Corning, NY, USA) was used to assess the effects of human pericytes and NELL-1 on endothelial cell morphogenesis. Briefly, $4 \times 10^{4}$ cells per well were added to Matrigel-pre-coated 96-well plates and treated with pericytes $\left(0.2 \times 10^{4}\right.$ cells/well) or NELL-1 $(800 \mathrm{ng} / \mathrm{mL})$, or both. Suramin $(40 \mathrm{mM}$; Sigma-Aldrich) was included as a negative control. After $12 \mathrm{~h}$, cell changes were recorded using a microscope (Nikon ECLIPSE Ti2) and analyzed using the Image J software program. This program provided automated quantitative measurements of tube characteristics (e.g., number of connected tubes, tube area, and angiogenic index).

\subsection{Wound Migration Assay}

HUVECs were added at a density of $3 \times 10^{3}$ cells per well in the ibidi Culture-Insert 2 Well in a $\mu$-Plate 24 Well plate and allowed to grow into a confluent monolayer overnight. A fresh medium containing indicated concentrations of human pericytes, and NELL-1 was added. The Culture-Insert 2 Well was then removed with sterile tweezers. After $24 \mathrm{~h}$, the cells were photographed using a JuLI ${ }^{\mathrm{TM}}$ Stage Cell History Recorder (NanoEntek, Guro-gu, Seoul, Korea). The migration rate was calculated using the JuLI ${ }^{\mathrm{TM}}$ Stage. A total of 3 measurements of 3 independent wounds were taken for each monolayer sample.

\subsection{Chick Chorioallantoic Membrane Assay}

The chick chorioallantoic membrane (CAM) assay was used to assess the effect of NELL-1 on ex vivo angiogenesis. Briefly, fertile chicken eggs were candled on embryonic day 3. A small opening was made at the top of the live eggs, and a sterilized Thermanox ${ }^{\mathrm{TM}}$ Coverslip (Nunc ${ }^{\mathrm{TM}}$ ) saturated with either PBS or NELL-1 was placed on the CAM. The holes were then sealed with cellophane tape. The eggs were photographed after a $72 \mathrm{~h}$ incubation. Image J software was used to quantify blood vessel density; the results were presented using bar diagrams [30].

\subsection{Animals}

A total of 24 8-week-old male NOD SCID mice (CHA Institute Animal Experimentation, Pangyo, Seongnam, Korea) were used for the study to prevent immune reactions to implants containing human cells. Each mouse was housed alone in a pathogen-free ventilated cage, fed a standard rodent chow diet, provided tap water ad libitum, and experienced $12 \mathrm{~h}$ light and dark cycles. The mice were cared for following the Chancellor's Animal Research Committee for Protection of Research Subjects guidelines at the CHA medical university (IACUC190082).

\subsection{Implant Preparation and Grouping}

Recombinant human NELL-1 was purchased from Bone Biologics Inc. (UCLA, Los Angeles, LA, USA). An absorbable collagen sponge (ACS) of defined dimensions $(0.5 \mathrm{~cm} \times$ $0.5 \mathrm{~cm} \times 1.0 \mathrm{~cm}$, Lyoplant, 1066102; Aesculap AG, Tuttlingen, Germany) was used. Because intramuscular implantation of ACS alone has no known bone-forming effects, this carrier was chosen for its non-osteoinductive characteristics [31]. Defined concentrations of viable 
cells and NELL-1 in PBS suspension $(20 \mu \mathrm{L})$ from the hSVF were applied and allowed to saturate the ACS. The cell and protein scaffold suspensions were kept on ice until implantation. The 4 treatment groups used were (a) control with PBS (b) high concentration (800 ng/mL) NELL-1, (c) pericytes, and (d) pericytes loaded with a high concentration $(800 \mathrm{ng} / \mathrm{mL})$ of NELL-1.

\subsection{Surgical Procedure for Mouse Models of Osteonecrosis}

We used a mouse model with a necrotic bone fragment to replace osteonecrosis in humans. A total of 30 mice (6 for control, 8 for NELL-group, 8 for the pericytes group, and 8 for the pericytes + NELL-1 group) were used for the experiment. All mice were prepared at the age of 3 months. Anesthesia was initiated in a 5\% gaseous isoflourane-filled holding chamber and maintained with 3-4\% gaseous isoflourane through a nose cone. Before making an incision, the thigh of the mouse was shaved, and the skin was prepared using an alcohol and betadine solution. Sterile ophthalmic lubricant ointment was applied to each eye, and a buprenorphine injection $(0.05 \mathrm{mg} / \mathrm{kg})$ was given via the subcutaneous route.

All surgical procedures were performed by the senior author, an experienced orthopedic surgeon. The femoral bone was exposed using an incision made on the anterolateral aspect of the thigh. A PEEK plate was located on the anterior femur. The most proximal hole of the plate was gently drilled using a $0.3 \mathrm{~mm}$ drill bit, and the first screw was inserted. Additional distal screws were inserted in a similar fashion. The $0.22 \mathrm{~mm}$ Gigli saw wire was closely placed around the bone in a mediolateral orientation and inserted in the slots of the customized jig to create a $2.5-\mathrm{mm}$ bone defect. The jig was inserted on the stem of the two last screws and applied above the plate. Next, a 2.5-mm long mid-diaphyseal femoral ostectomy was performed using the Gigli saw while applying a constant steady tension. Care was taken to avoid excess movement to obtain a straight bone cut. After the ostectomy, the Gigli saw was removed, and the saw wire was cut close to the bone on one side. The jig and remaining stem of the screw were removed. The bone fragment from the ostectomy was removed and immersed in liquid nitrogen for $5 \mathrm{~min}$ to induce necrosis. The ACS treated with the assigned material based on the treatment group ( \pm pericytes \pm NELL-1) was put below the femoral shaft and the necrotic bone fragment was taken back to the original site. It was then wrapped using the ACS. Finally, the ACS was sutured to prevent displacement of the necrotic bone fragment, and the wound was closed (Figure 1).
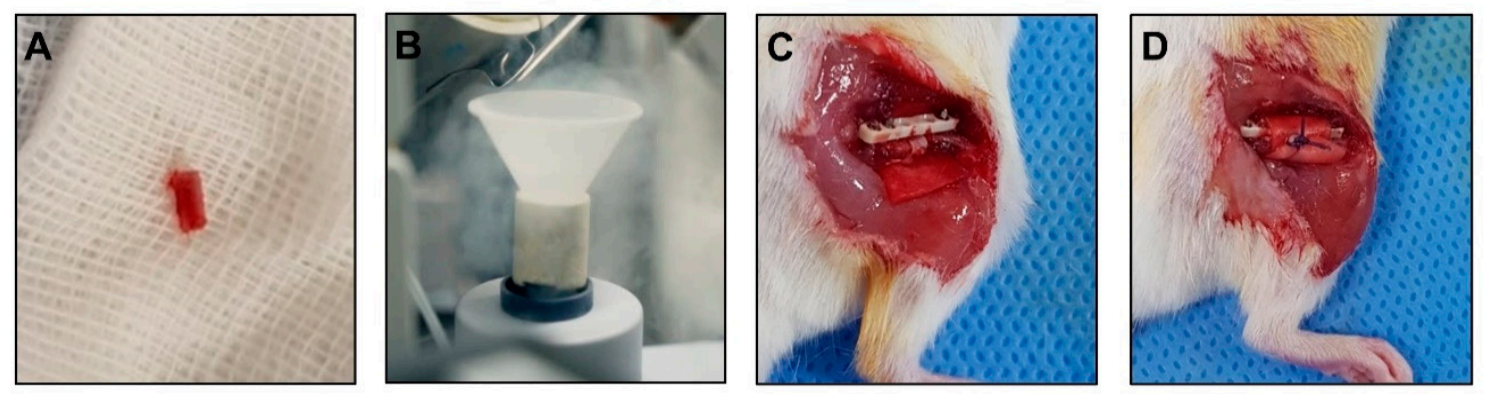

Figure 1. Procedures for the mouse model of osteonecrosis. (A) After ostectomy, bone fragments were removed. (B) The bone fragment was immersed in liquid nitrogen for $5 \mathrm{~min}$. (C) An absorbable collagen sponge (ACS), with or without pericytes and NELL-1, was placed below the femoral shaft. Necrotic bone fragments were transferred to the site with defects.

(D) The necrotic bone fragment was wrapped by suturing the ACS to prevent displacement.

\subsection{In Vivo Plain Radiograph}

In vivo bone regeneration was assessed using plain radiography images (GIX-I, Genoray, Seongnam, Korea; Ultra Light Portable X-ray, Nanoray, Deagu, Korea) of the femur under the conditions of $70 \mathrm{kV} / 20 \mathrm{~mA}, 0.06 \mathrm{~s} ; 20$ lines per mm spatial resolution. Standard lateral digital radiographs of the femur were taken immediately after surgery and 4 weeks later under volatile anesthesia [32]. 


\subsection{Ex Vivo Micro Computed Tomography}

The mice were euthanized using $\mathrm{CO}_{2}$ asphyxiation 4 weeks after surgery. Highresolution micro-computed tomography (CT) scanning of each sample was performed (Bruker microCT Skyscan 1173). Each piece of femur bone was in a polyethylene tube filled with alcohol (75 volume percent) during scanning. The radiographic projections were acquired at $130 \mathrm{kV}$ and $60 \mathrm{uA}$ with a fixed exposure time of $500 \mathrm{~ms}$, an A1 $1.0 \mathrm{~mm}$ filter, and a 6.04 um pixel size. Four frames were averaged for each rotation increment of 0.9. Three-dimensional images with an average voxel size of $13 \mathrm{~mm}$ were reconstructed using a Hamming-filtered back-projection and the manufacturer's reconstruction software (NRecon; Skyscan, Aartselaar, Belgium). Bone mineral density (BMD) of the femur was measured using the Bruker microCT with a phantom. The analyses were performed in the same manner for each mouse, with a volume of interest corresponding to the respective defect. The number of united cortices in 2 orthogonal reconstructed views was recorded for the qualitative analysis. Bone union was defined as a union of 4 out of 4 cortices. Resident software (CTAn; Skyscan, Aartselaar, Belgium) was used to obtain the BV/TV and BMD for quantitative analysis of bone formation within a region of interest. A lower gray threshold of 45 grayscale indices (attenuation coefficient of 0.035) and an upper gray threshold of 240 grayscale indices (attenuation coefficient of 0.186 ) were used for each mouse [33].

\subsection{Histology and Histomorphometric Analysis}

The animals were euthanized 4 weeks after surgery. Histologic specimens were fixed in $4 \%$ paraformaldehyde at $4{ }^{\circ} \mathrm{C}$ for $1 \mathrm{~d}$, followed by decalcification (Calci-Clear ${ }^{\mathrm{TM}}$ Rapid Decalcifying Solution, HS-105; National Diagnostics) for $3 \mathrm{~h}$ at room temperature with gentle mechanical stirring. The specimens were then dehydrated and embedded in paraffin. The tissue blocks were sectioned to $3 \mathrm{~mm}$ thicknesses along longitudinal planes (Leica RM2235 microtome; Leica Microsystems GmbH, Wetzlar, Germany). All sections were stained with hematoxylin and eosin and alcian blue staining.

Immunohistochemistry (IHC) was performed using a ready-to-use IHC/ICC kit (BioVision, Inc.) according to the manufacturer's protocol. Briefly, slides were deparaffinized, rehydrated, and microwaved in citrate buffer (cat. no. ab93678; Abcam) for antigen retrieval. The slides were incubated in $3 \% \mathrm{H} 2 \mathrm{O} 2$ at room temperature for $30 \mathrm{~min}$ to quench endogenous peroxi- dase activity, and then blocked in blocking buffer (BioVision, Inc.), followed by incubation with CD31 (Cell signaling, cat. no. \#77699, 1:100), or VEGF (Abcam, cat. no. MA5-13182,1:100) antibodies at room temperature for $30 \mathrm{~min}$. After incubation with HRP-anti-mouse or -rabbit IgG polymer at room temperature, the sections were treated with 3,3'-diaminobenzidine at room temperature for $10 \mathrm{~min}$, followed by counterstaining. Images were captured with an Eclips-TS2 microscope.

\subsection{Microarray}

Microarrays were used to measure expression levels of genes related to NELL-1 activity. NELL-1 treated pericyte samples were used. Briefly, total RNA was isolated using RNeasy columns (Qiagen, Valencia, CA, USA) according to the manufacturer's protocol. The RNA samples were quantified after processing with DNase digestion and clean-up procedures. An Ambion Illumina RNA amplification kit (Ambion, Austin, TX, USA) was used to amplify and purify the total RNA. Total RNA (550 ng) from each sample was converted to double-strand cDNA. Using a T7 oligo (dT) primer, amplified RNA (cRNA) was generated from the double-stranded cDNA template using an in vitro transcription reaction and purified using the Affymetrix sample clean-up module. An ND-1000 Spectrophotometer (NanoDrop, Wilmington, DE, USA) was used to quantify cDNA after purification. UracilDNA glycosylase and apurinic/apyrimidinic endonuclease and restriction endonucleases were used to fragment the cDNA. It was end-labeled using a terminal transferase reaction incorporating a biotinylated dideoxynucleotide. Fragmented end-labeled cDNA was hybridized to the GeneChip Human Gene 2.0 ST arrays manual (Affymetrix, Santa Clara, CA, USA). After hybridization, the chips were stained and washed (GeneChip Fluidics 
Station 450; Affymetrix) and scanned (GeneChip Array scanner 3000 G7; Affymetrix) by Macrogen Ltd. (Seoul, South Korea). Affymetrix ${ }^{\circledR}$ GeneChip ${ }^{\mathrm{TM}}$ Command Console software was used to compute signal values.

\subsection{RNA Isolation and QRT-PCR Analysis}

Total RNA was extracted from cells using Trizol reagent (Invitrogen), according to the manufacturers' instruction. One micrograms of total RNA were used to determine the expression of mRNAs using AMPIGENE ${ }^{\circledR}$ qPCR Green Mix (Enzo Biochem, Inc., New York, NY, USA) and iCycler real-time PCR detection system (Bio-Rad, CA) according to the manufacturers' instruction. The sequences of the primers were as follows: FGF2, $5^{\prime}-$ AGAAGAGCGACCCTCACATCA-3' (forward) and 5'-CGGTTAGCACACACTCCTTTG-3' (reverse); IL-6, 5'-ACTCACCTCTTCAGAACGAATTG-3' (forward) and 5' -CCATCTTTGG AAGGTTCAGGTTG-3' (reverse); TGFB2, 5' -CAGCACACTCGATATGGACCA-3' (forward) and $5^{\prime}$-CCTCGGGCTCAGGATAGTCT-3' (reverse); VEGFA, 5' -AGGGCAGAATCATCACG AAGT-3' (forward) and 5'-AGGGTCTCGATTGGATGGCA-3' (reverse); $\beta$-actin, $5^{\prime}$-ACCGA GCGCGGCTACAG-3' (forward) and 5'-CTTAATGTCACGCACGATTTCC- $3^{\prime}$. $\beta$-actin was used for the normalization of mRNA.

\subsection{Western Blot}

Protein extraction buffer (Pro-Prep, iNtRON Biotechnology, Gyeonggi-do, Korea) was used to lyse cells for Western blot. After centrifugation $\left(4^{\circ} \mathrm{C}, 13,000 \mathrm{rpm}\right.$ for $\left.15 \mathrm{~min}\right)$, protein content of lysed cells was assessed (Bradford assay). Equal total protein amounts were run on $12 \%$ SDS polyacrylamide gels and transferred to a nitrocellulose membrane. Membranes were blocked using 5\% non-fat milk powder at room temperature and then incubated with primary antibodies in tris-buffered saline-tween 20 (TBS-T) overnight at $4{ }^{\circ} \mathrm{C}$. The primary antibodies against FGF2 (cat. no. sc-271930, 1:1000), GAPDH (cat.no. sc-47724, 1:3000) were purchased from Santa Cruz Biotechnology, Inc. Antibodies against phospho-PLC $\gamma$ (cat.no. \#8713, 1:1000), PLC $\gamma$ (cat.no \#5690, 1:1000), phospho-AKT (cat.no. \#4060, 1:1000), AKT (cat.no. \#4691, 1:1000), phospho-ERK (cat.no. \#4370, 1:1000), ERK (cat.no \#4695, 1:1000), phospho-eNOS (cat.no. \#9570, 1:1000), eNOS (cat.no. \#32027, 1:1000) were purchased from Cell Signaling Technology, Inc.

The membranes were then washed in TBS-T and incubated with 1:5000 goat antimouse IgG (Santa Cruz Biotechnology) secondary antibodies for $1 \mathrm{~h}$ at room temperature. An enhanced luminol-based chemiluminescence detection kit (Bio-Rad Laboratories, Hercules, CA, USA) was used to visualize the resulting bands. Protein quantification was performed using densitometric digital analysis of the protein bands (ChemiDoc ${ }^{\mathrm{TM}} \mathrm{XRS}+$ with Image Lab ${ }^{\mathrm{TM}}$ Software ver. 6.0; Bio-Rad Laboratories). The membrane was re-probed with GAPDH (Santa Cruz Biotechnology) to confirm equal loading. After each sample was run at least 3 times on Western blot analysis, densitometry analysis was performed for each of the 3 bands.

\subsection{Statistical Analysis}

All data were presented as the mean \pm SEM. All statistical analyses were performed using SPSS 17.0 (SPSS, Inc.) and GraphPad Prism software 5 (GraphPad Software, Inc.). Student's t-test was used to compare the difference between 2 groups, and one-way ANOVA with post hoc Tukey's test was performed to compare the differences among more than 2 groups.

\section{Results}

3.1. Pericytes and NELL-1 Promote Angiogenesis and Migration of HUVECs In Vitro and during Embryonic Vascularization In Vivo

To assess whether pericytes and NELL-1 affected angiogenesis of HUVECs in vitro, the HUVECs were treated with pericytes alone (pericyte group; PG), NELL-1 alone (NELL1 group: NG) or pericytes and NELL-1 (pericytes + NELL-1 group; PNG). The results 
indicated that the PG had significantly greater numbers of tubes and branch points than the control group that had HUVECs alone. The presence of pericytes increased tube formation, and this increase intensified with the addition of NELL-1. Further, the addition of NELL-1 induced greater numbers of tubes and branch points than in the control group. In particular, the number of branch points in the PNG was greater than in the PG (Figure 2A). In addition, it was confirmed that the proliferation of HUVECs was slightly increased in the PNG group compared to the control group (Figure 2B). Because endothelial cell migration has an important role in angiogenesis [15], the effect of NELL-1 on wound closure was studied using a HUVEC scratch assay. We found that the PNG showed markedly induced HUVEC migration compared with the PG (Figure 2C).

A
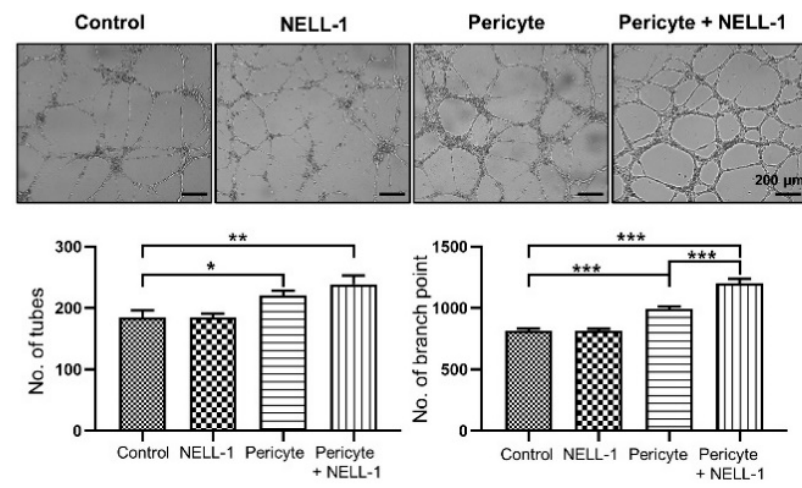

B

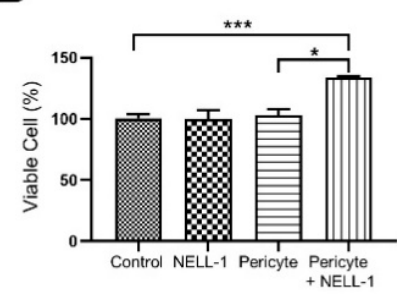

C
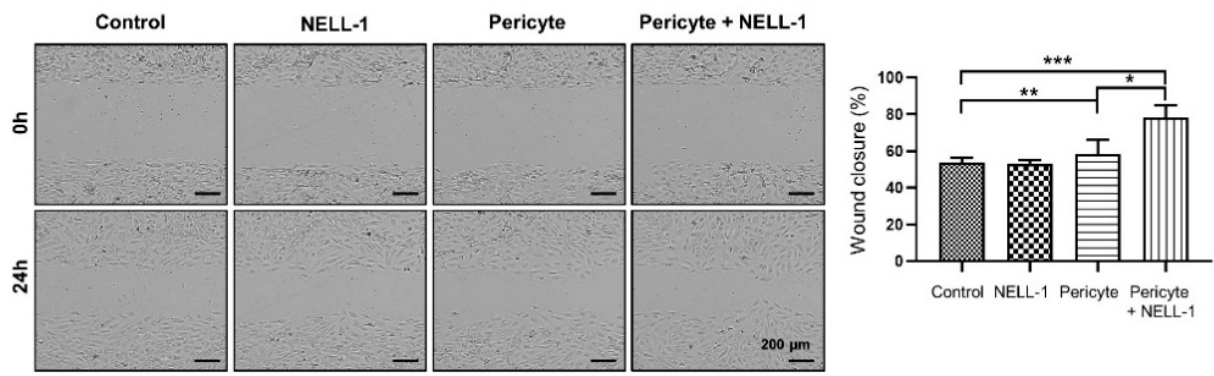

Figure 2. Pericytes and NELL-1 promote angiogenesis and migration of HUVECs. (A) Pericytes and NELL-1 promote tube formation of HUVECs. Matrigel-coated 96-well plates were seeded with HUVECs $\left(4 \times 10^{4}\right)$ treated with pericytes and NELL-1 $(800 \mathrm{ng} / \mathrm{mL})$. After a $12 \mathrm{~h}$ incubation, a Nikon ECLIPSE Ti2 and analyzed using the Image J software program. Tube number was quantified using the Image-Pro Plus 6.0 software. (B) Pericytes and NELL-1 promote the viability of HUVECs in WST1 assays. 96-well plates were seeded with HUVECs $\left(41.5 \times 10^{4}\right)$ treated with pericytes and NELL-1 (800 ng/mL). (C) Pericytes and NELL-1 promote migration of HUVECs in wound-healing assays. HUVECs were treated with or without NELL-1 $(800 \mathrm{ng} / \mathrm{mL})$ for $24 \mathrm{~h}$. Cells were photographed using a JuLI ${ }^{\mathrm{TM}}$ Stage Cell History Recorder (NanoEntek, Guro-gu, Seoul, Korea). The migration rate was calculated using the JuLI ${ }^{\mathrm{TM}}$ Stage. Data were obtained from 3 independent experiments. Error bars represent mean \pm SEM. ${ }^{*} p<0.05 ;{ }^{* *} p<0.01 ;{ }^{* * *} p<0.001$. Scale bar: $200 \mu \mathrm{m}$.

Next, we performed a CAM assay to examine the angiogenic effects of NELL-1 in vivo. The assay results indicated that during embryonic vascularization, blood vessels in the NELL-1-treated group showed significantly greater vessel density and total numbers of segments and branching points compared with the control group. The results indicated that NELL-1 induced angiogenesis in vivo (Figure 3). 

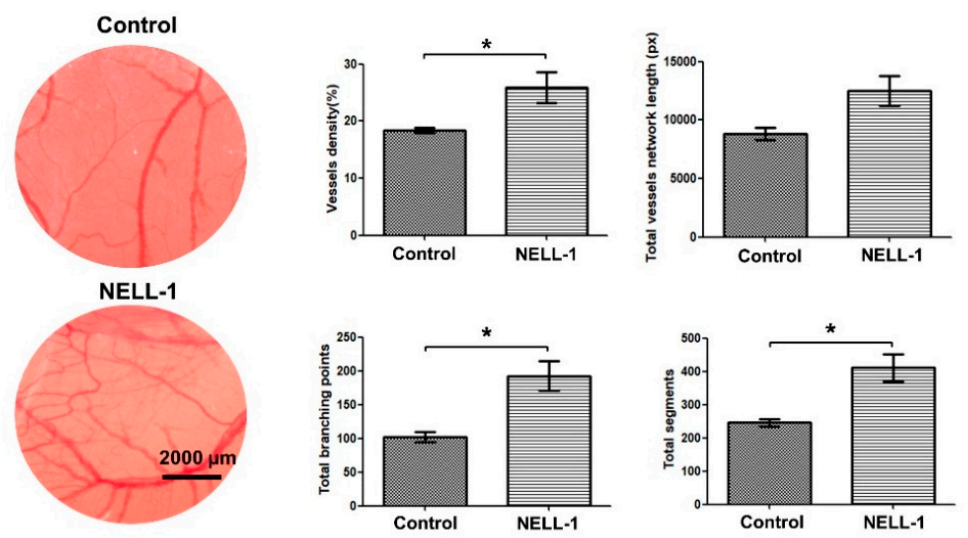

Figure 3. NELL-1 protein enhances angiogenesis. Representative images of chick chorioallantoic membrane in CAM assays. Fertilized eggs were treated with NELL-1 $(800 \mathrm{ng} / \mathrm{mL})$ for $72 \mathrm{~h}$, along with non-treated controls. Microvessel images were captured using an EVOS FL Cell Imaging System (magnification: $\times 10$ ). Data were obtained from 3 independent experiments. Error bars represent mean \pm SEM. ${ }^{*} p<0.05$. Scale bar: $2000 \mu \mathrm{m}$.

\subsection{Pericytes and NELL-1 Promote Bone Formation In Vivo}

To investigate the effectiveness of NELL-1 in vivo, we established an osteonecrosis model using mice and implanted femurs with pericytes alone (PG), or pericytes and NELL1 (PNG) (Figure 4A). Plain radiographs and three-dimensional imaging indicated that femurs treated with pericytes, and NELL-1 (PNG) showed the greatest bone formation compared with other treatments (Figure 4B). The microCT results indicated that greater gains in BV/TV and BMD occurred in the PNG than in the PG (Figure 4C). Next, we examined the extent of osteocytic death via the quantification of empty lacunae in each group. We observed a synergistic decrease in the fraction of empty lacunae in PNG. In addition, Immunohistochemical analysis showed that CD31 and VEGF expression was higher in the PNG than in the PG, indicating that angiogenesis was induced in these groups (Figure 5).

A
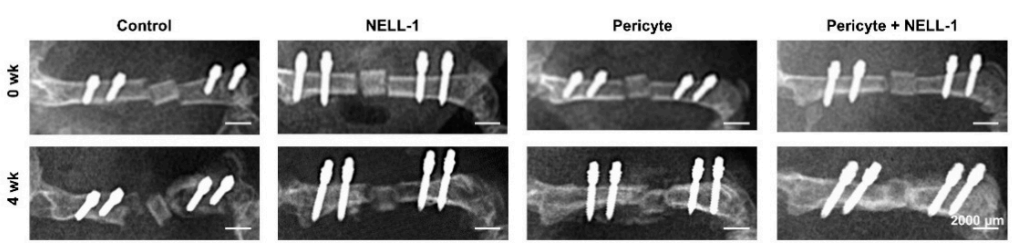

B

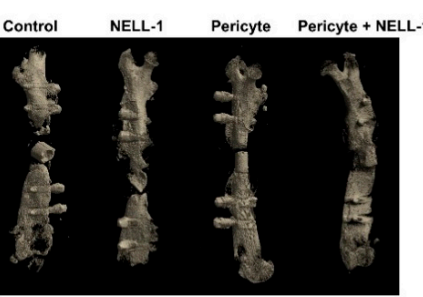

C
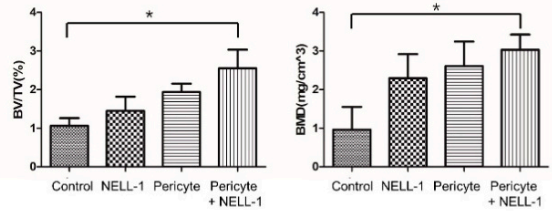

Figure 4. Pericytes and NELL-1 promote bone formation in an animal model for osteonecrosis. (A) The upper four images were taken immediately after surgical procedures. The lower four images were taken 4 weeks after surgical procedures and show the bone union of necrotic bone treated with pericytes and NELL-1. (B) Representative images of femurs isolated from pericytes treated with or without NELL-1 mice were generated using $\mu \mathrm{CT}$. (C) BV/TV and BMD of the femurs $(n=6)$ were analyzed using a $\mu \mathrm{CT}$ scanner and CTAn software * Maximum effect compared with other treatments; ${ }^{*} p<0.05$. Scale bar: $2000 \mu \mathrm{m}$. 

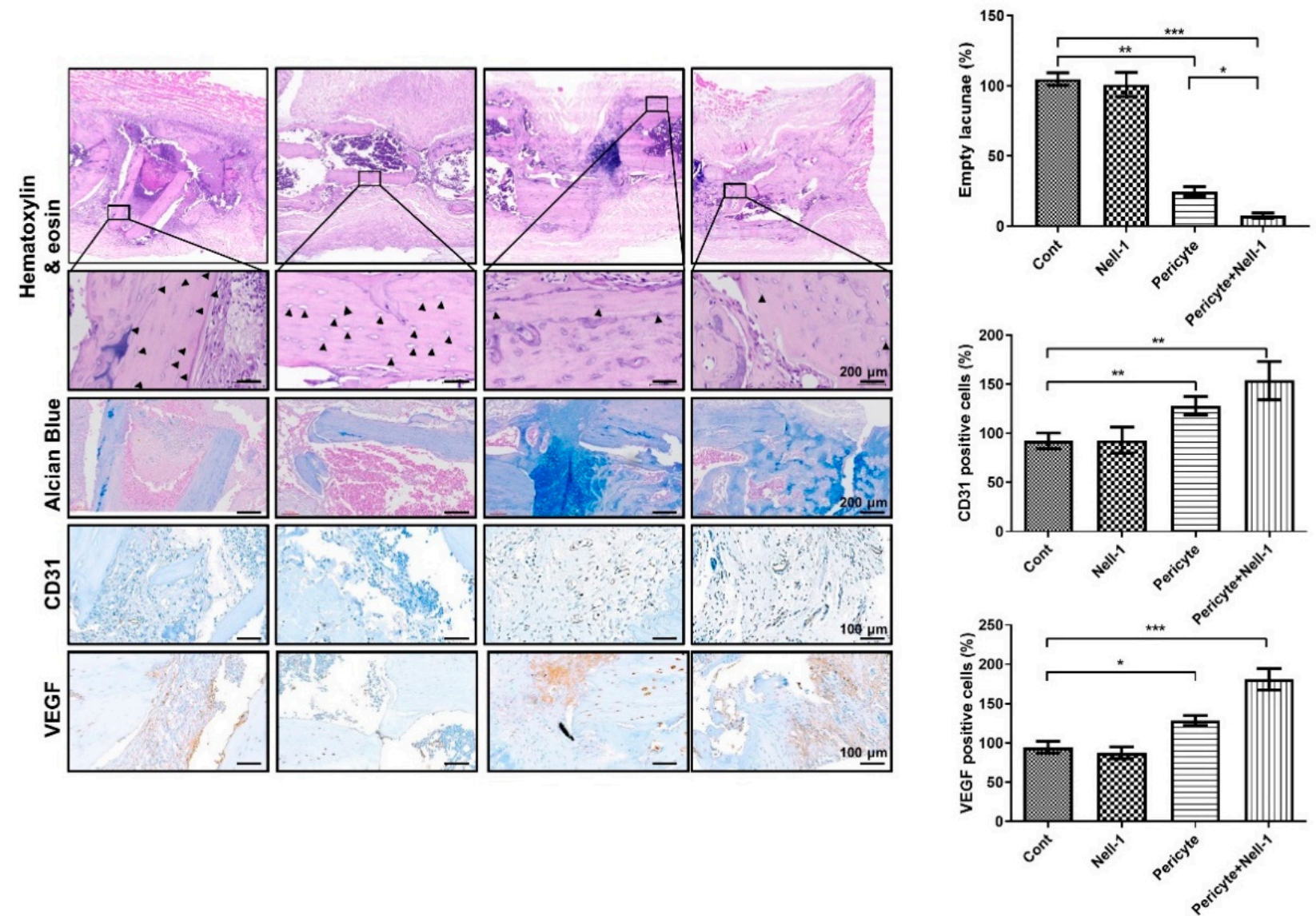

Figure 5. Immunohistochemical analysis of femur sections using hematoxylin and eosin (H\&E) staining, Alcian Bluestain, and other relevant proteins. Immunohistochemical analysis of femur sections using hematoxylin and eosin (H\&E) staining, Alcian Blue, and angiogenesis markers for CD31 and VEGF. At the end of the in vivo study, small femur sections taken from all groups were decalcified in EDTA, fixed in formalin, paraffin-embedded, sectioned, and immunostained using H\&E (upper panel), Alcian Blue (second panel), CD31 (third panel), and VEGF (lower panel). The right panel shows the quantification data for immunohistochemical staining and the percentage of empty lacunae relative to the total lacunae. ${ }^{*} p<0.05 ;{ }^{* *} p<0.01 ;{ }^{* *} p<0.001$. Images were taken at the magnification indicated. Scale bars indicate $200 \mu \mathrm{m}$ for H\&E, Alcian Blue images, and $100 \mu \mathrm{m}$ for CD31, VEGF images.

\subsection{NELL-1 Promotes the FGF2 Signaling Pathway}

To identify the pathways associated with the NELL-1-dependent pro-angiogenic and osteogenic effects, we performed heatmap analysis using microarray data to compare the control versus NELL-1 treated pericytes. We identified four candidate genes (FGF2, IL6, TGFB2, and VEGFA) from among those upregulated by NELL-1 (Figure 6A,B), and also examined whether NELL-1 modulated the FGF2 pathway. NELL-1 induced an increase in FGF2 protein levels and the direct downstream targets of p-PLC $\gamma, p-A K T, p-E R K$, and peNOS. The results indicate that NELL-1 induced pro-angiogenic and osteogenic pathways (Figure 6C). 
A

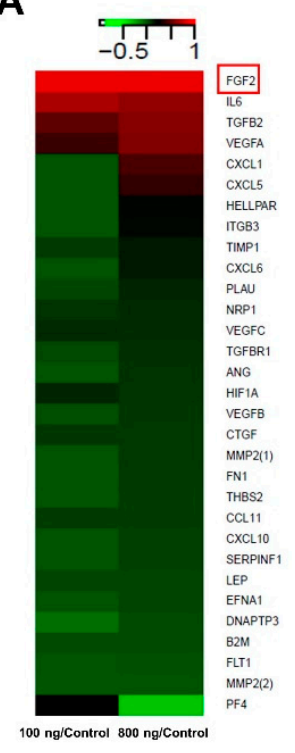

B
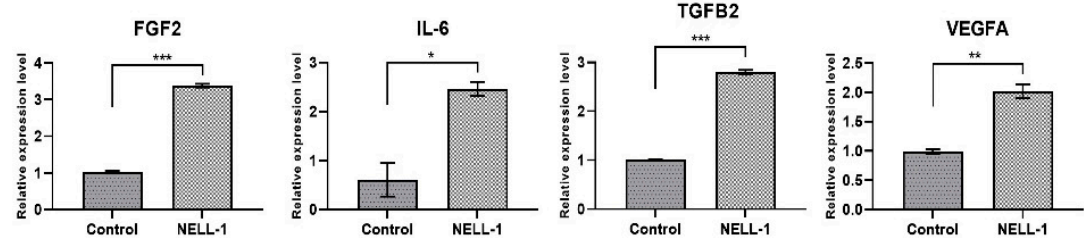

C
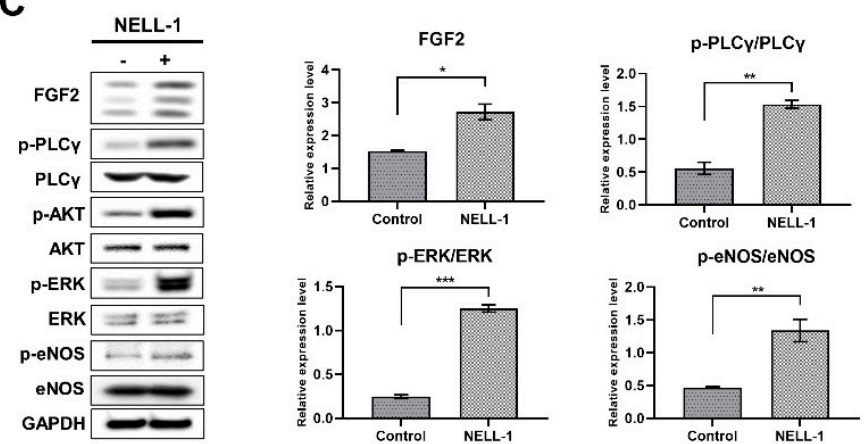

Figure 6. NELL-1 increases FGF2-AKT-eNOS pathway signaling. (A) Heatmap showing temporal expression patterns of angiogenesis-related mRNAs identified using pericytes treated with NELL-1 (100 ng/mL or $800 \mathrm{ng} / \mathrm{mL})$. Z-scores of normalized read counts are indicated by the colored bars. Red: high expression; green: low expression. (B) Validation of selected differentially expressed mRNAs in pericytes treated with NELL-1 ( $800 \mathrm{ng} / \mathrm{mL})$ via qRT-PCR. $\beta$-actin was used as a normalization control. Data were obtained from 3 independent experiments. Error bars represent mean \pm SEM. (C) Western blot analysis of FGF2 pathway-related proteins after $72 \mathrm{~h}$ of stimulation with $800 \mathrm{ng} / \mathrm{mL}$ NELL-1. Data were obtained from 3 independent experiments. Error bars represent mean \pm SEM. ${ }^{*} p<0.05 ;{ }^{* *} p<0.01 ;{ }^{* * *} p<0.001$.

\section{Discussion}

The principal finding of this study relates to the NELL-1 dependent induction of angiogenesis and osteogenesis by pericytes. Pericytes combined with NELL-1 administration induced a synergistic effect during angiogenesis and osteogenesis [7], which are critically coupled processes for bone regeneration [34]. Vascular control is required for bone health. Blood vessels are key regulators of bone homeostasis because they serve as structural templates and provide nutrients and minerals [35]. Changes in vascular growth can negatively affect physiological bone healing and result in osteonecrosis [36]. The development of animal models to test novel cell-based therapeutic options that can prevent or delay osteonecrosis progression has been the focus of basic science and clinical research in this field. Cell-based therapies have been administered along with surgical treatment and resulted in significant improvements in survival compared with surgical treatment alone [6]. Given the growing evidence for the effectiveness and non-invasiveness of regenerative therapies, intensified efforts and studies to identify the efficacy of novel agents are necessary. To the best of our knowledge, this is the first study to use a mouse model with a necrotic bone fragment that mimics osteonecrosis in humans and highlights the potential of the combined application of stem cells (pericytes) and an osteoinductive protein (NELL-1) in vivo. We hypothesized that treatment with pericytes and NELL-1 could reverse osteonecrosis lesions. An osteogeneic and angiogenic potent effect was observed after local delivery, which was supported by radiographic images and histologic findings.

Large animals such as canines [37], pigs [38], and sheep [39] have been used as models to induce osteonecrosis. However, designing a series of experiments with these animals can be a limiting factor due to high costs. The use of rodents such as mice incurs relatively lower costs and is feasible for studies having large sample sizes. However, mouse models are somewhat small for surgical procedures. An ideal animal model should be cost-effective and large enough to perform various procedures. Considering these points, we selected 
the femoral shaft in mice instead of the proximal or distal end of the femur for analysis. We believe that our mouse model may provide the benefit of low cost and relatively large bone size to enable surgical procedures.

The regenerative potential of pericytes depends on the tissue of origin. We isolated and used AD pericytes that show efficient osteogenic differentiation [40]. To evaluate the effect of NELL-1 addition on pericytes, the concentration of NELL-1 required in the assay was analyzed and was based on the results of Zhang et al.'s study [25], which showed the effect of NELL-1 on bone formation. In addition, the effect of NELL-1 on pericyte proliferation using viability and WST-1 assays was assessed. The proliferation of pericytes without NELL-1 treatment and those treated with $100 \mathrm{ng} / \mathrm{mL}$ or $800 \mathrm{ng} / \mathrm{mL}$ NELL-1 was compared. Our results showed that no significant differences were observed between the three groups (Data not shown), indicating that the direct effect of NELL-1 on pericyte proliferation was not significant. We hypothesized that concentrations between 100 and $800 \mathrm{ng} / \mathrm{mL}$ were feasible for subsequent assays; and selected the highest concentration $(800 \mathrm{ng} / \mathrm{mL})$ to maximize the effect on proliferation and assessed osteogenic differentiation (Data not shown).

The effect of the pericyte-endothelial cell ratio on angiogenic potential has been examined [40]. Based on their results, Herrmann et al. used 10\% pericytes and $90 \%$ HUVECs in their analyses [40]. We used a 1:20 ratio of pericytes:HUVECs that was chosen based on an optimal vascular tube growth and stability protocol (VascuNet ${ }^{\mathrm{TM}}$ Pericyte CoCulture Assay; ESI BIO, Alameda, USA). We found synergistic effects between pericytes and NELL-1, and thus, the methods used in our analysis are feasible options for future studies.

Tube formation in HUVECs treated with NELL-1 without pericytes did not differ significantly compared with the control (Figure 2A), and NELL-1 did not have a direct effect on tube formation. Taken together, the results indicated that NELL-1 affected cell migration when used in combination with pericytes and affected the efficacy of pericytes due to an increase in FGF2 signaling. FGF2 has a well-characterized ability to regulate the growth and function of vascular cells such as endothelial and smooth muscle cells, and is a growth factor that increases vascularization, induces angiogenesis [41], and stimulates mitogenesis of mesenchymal progenitors and osteoblasts [42]. Future studies should aim at understanding the detailed mechanisms underlying NELL-1 activity when combined with pericytes, especially in the context of FGF2-dependent signaling.

This study has a few limitations. As the study shows the results of preclinical research, additional studies and evidence are required for clinical application. Nevertheless, we believe that our mouse model is relevant for assessing bone regeneration because treatment with pericytes and NELL-1 resulted in robust bone and vessel formation. Therefore, we believe that our mouse model may simplify the analysis of osteonecrosis in humans. Further, the reliability of mouse models to study osteonecrosis is questionable, and our mouse model may serve as a reliable option because ostectomy using the customized jig and the Gigli saw is much simpler than cauterization of vessels to directly induce ischemic osteonecrosis [43]. For consistency, all surgical procedures in this study were performed by the senior author, an experienced orthopedic surgeon. Lastly, the sequence of vessel maturation in angiogenesis was not evaluated. However, we assessed bone regeneration that resulted from the critically coupled processes of angiogenesis and osteogenesis.

\section{Conclusions}

The results of our study indicated that AD pericytes combined with NELL-1 treatment synergistically enhanced the sequence of angiogenesis. We used a mouse model of osteonecrosis and identified significant bone formation using radiographic images and histologic analysis. Thus, combination therapy using AD pericytes and NELL-1 may have potential as a novel treatment for osteonecrosis. 
Author Contributions: H.-J.A. and K.R.K. reviewed, edited, and revised the manuscript, provided administrative support, and analyzed data. They contributed equally and should be considered as co-first authors. M.B., Y.J., H.H.L., H.K., D.K.K. and S.-Y.L. collected and analyzed data. S.L. designed the study, wrote, reviewed, and edited the manuscript, and supervised the work. All authors have read and agreed to the published version of the manuscript.

Funding: Hyun-Ju An received a National Research Foundation Grant of Korea (NRF-2020R1I1A1A 01073917), funded by the Korean government (Available online: https: / / www.nrf.re.kr (accessed on 1 June 2020)) for this work. So-Young Lee received National Research Foundation Grant of Korea (NRF2019R1A2C4070492), funded by the Korean government (Available online: https://www.nrf.re.kr (accessed on 1 March 2019)) for this work. Soonchul Lee received National Research Foundation Grant of Korea (NRF-2019R1C1C1004017), funded by the Korean government (Available online: https: / /www.nrf.re.kr (accessed on 1 March 2019)) for this work.

Institutional Review Board Statement: The mice used in the present study were maintained according to guidelines approved by the Institutional Animal Care and Use Committee of CHA medical university (IACUC; permit No. 190082) and were conducted according to AVMA guidelines. Collection and use surgical human tissues were approved by the Institutional Review Board (IRB) of CHA medical university (IRB; Permit No. 2018-05-036). The study was conducted in accordance with the Declaration of Helsinki. Pericyte were collected from donors after obtaining their informed consent.

Informed Consent Statement: Informed consent was obtained from all subjects involved in the study.

Data Availability Statement: The authors confirm that the data supporting the findings of this study are available within the article.

Acknowledgments: The NELL-1 was kindly provided by Kang Ting, Chia Soo, and Xinli Zhang (UCLA, USA). We thank them for materials, helpful discussions, and technical assistance. And Cathy Liu and Georg Breier for the editorial assistance.

Conflicts of Interest: The authors declare that they have no competing interest.

\section{Abbreviations}

$\begin{array}{ll}\text { AD } & \text { adipose tissue-derived } \\ \text { NELL-1 } & \text { Nel-like protein-1 } \\ \text { ONFH } & \text { osteonecrosis of the femoral head } \\ \text { hSVF } & \text { human stromal vascular fraction } \\ \text { PBS } & \text { phosphate buffered saline } \\ \text { DMEM } & \text { dulbecco's modified eagle's medium } \\ \text { FACS } & \text { fluorescence-activated cell sorter } \\ \text { FBS } & \text { fetal bovine serum } \\ \text { HUVECs } & \text { human umbilical vein endothelial cells } \\ \text { WST } & \text { water-soluble tetrazolium salt } \\ \text { CAM } & \text { chick chorioallantoic membrane } \\ \text { ACS } & \text { absorbable collagen sponge } \\ \text { CT } & \text { computed tomography } \\ \text { BMD } & \text { bone mineral density } \\ \text { PG } & \text { pericytes group } \\ \text { PNG } & \text { pericytes + NELL-1 group }\end{array}$

\section{References}

1. DeCicco-Skinner, K.L.; Henry, G.H.; Cataisson, C.; Tabib, T.; Gwilliam, J.C.; Watson, N.J.; Bullwinkle, E.M.; Falkenburg, L.; O'Neill, R.C.; Morin, A.; et al. Endothelial cell tube formation assay for the in vitro study of angiogenesis. JoVE 2014, 91 , e51312. [CrossRef]

2. Van Hove, A.H.; Benoit, D.S. Depot-Based Delivery Systems for Pro-Angiogenic Peptides: A Review. Front. Bioeng. Biotechnol. 2015, 3, 102. [CrossRef] [PubMed]

3. Carmeliet, P.; Jain, R.K. Angiogenesis in cancer and other diseases. Nature 2000, 407, 249-257. [CrossRef] [PubMed]

4. Nugent, M.; Young, S.W.; Frampton, C.M.; Hooper, G.J. The lifetime risk of revision following total hip arthroplasty. Bone Jt. J. 2021, 103-B, 479-485. [CrossRef] [PubMed]

5. Lieberman, J.R. Core decompression for osteonecrosis of the hip. Clin. Orthop. Relat. Res. 2004, 418, 29-33. [CrossRef] 
6. Andriolo, L.; Merli, G.; Tobar, C.; Altamura, S.A.; Kon, E.; Filardo, G. Regenerative therapies increase survivorship of avascular necrosis of the femoral head: A systematic review and meta-analysis. Int. Orthop. 2018, 42, 1689-1704. [CrossRef]

7. Askarinam, A.; James, A.W.; Zara, J.N.; Goyal, R.; Corselli, M.; Pan, A.; Liang, P.; Chang, L.; Rackohn, T.; Stoker, D.; et al. Human perivascular stem cells show enhanced osteogenesis and vasculogenesis with Nel-like molecule I protein. Tissue Eng. Part. A 2013, 19, 1386-1397. [CrossRef] [PubMed]

8. Lee, S.; Zhang, X.; Shen, J.; James, A.W.; Chung, C.G.; Hardy, R.; Li, C.; Girgius, C.; Zhang, Y.; Stoker, D.; et al. Brief Report: Human Perivascular Stem Cells and Nel-Like Protein-1 Synergistically Enhance Spinal Fusion in Osteoporotic Rats. Stem Cells 2015, 33, 3158-3163. [CrossRef]

9. Crisan, M.; Yap, S.; Casteilla, L.; Chen, C.W.; Corselli, M.; Park, T.S.; Andriolo, G.; Sun, B.; Zheng, B.; Zhang, L.; et al. A perivascular origin for mesenchymal stem cells in multiple human organs. Cell Stem Cell 2008, 3, 301-313. [CrossRef]

10. Chen, C.W.; Montelatici, E.; Crisan, M.; Corselli, M.; Huard, J.; Lazzari, L.; Peault, B. Perivascular multi-lineage progenitor cells in human organs: Regenerative units, cytokine sources or both? Cytokine Growth Factor Rev. 2009, 20, 429-434. [CrossRef]

11. Corselli, M.; Chen, C.W.; Sun, B.; Yap, S.; Rubin, J.P.; Peault, B. The tunica adventitia of human arteries and veins as a source of mesenchymal stem cells. Stem Cells Dev. 2012, 21, 1299-1308. [CrossRef] [PubMed]

12. Crisan, M.; Corselli, M.; Chen, W.C.; Peault, B. Perivascular cells for regenerative medicine. J. Cell Mol. Med. 2012, 16, 2851-2860. [CrossRef]

13. Canfield, A.E.; Doherty, M.J.; Wood, A.C.; Farrington, C.; Ashton, B.; Begum, N.; Harvey, B.; Poole, A.; Grant, M.E.; Boot-Handford, R.P. Role of pericytes in vascular calcification: A review. Z. Fur Kardiol. 2000, 89 (Suppl. 2), 20-27. [CrossRef]

14. Schor, A.M.; Allen, T.D.; Canfield, A.E.; Sloan, P.; Schor, S.L. Pericytes derived from the retinal microvasculature undergo calcification in vitro. J. Cell Sci. 1990, 97 Pt 3, 449-461. [CrossRef]

15. Gerhardt, H.; Betsholtz, C. Endothelial-pericyte interactions in angiogenesis. Cell Tissue Res. 2003, 314, 15-23. [CrossRef] [PubMed]

16. Stallcup, W.B.; You, W.K.; Kucharova, K.; Cejudo-Martin, P.; Yotsumoto, F. NG2 Proteoglycan-Dependent Contributions of Pericytes and Macrophages to Brain Tumor Vascularization and Progression. Microcirculation 2016, 23, 122-133. [CrossRef]

17. Stapor, P.C.; Sweat, R.S.; Dashti, D.C.; Betancourt, A.M.; Murfee, W.L. Pericyte dynamics during angiogenesis: New insights from new identities. J. Vasc. Res. 2014, 51, 163-174. [CrossRef] [PubMed]

18. Ting, K.; Vastardis, H.; Mulliken, J.B.; Soo, C.; Tieu, A.; Do, H.; Kwong, E.; Bertolami, C.N.; Kawamoto, H.; Kuroda, S.; et al. Human NELL-1 expressed in unilateral coronal synostosis. J. Bone Miner. Res. 1999, 14, 80-89. [CrossRef]

19. Aghaloo, T.; Cowan, C.M.; Chou, Y.F.; Zhang, X.; Lee, H.; Miao, S.; Hong, N.; Kuroda, S.; Wu, B.; Ting, K.; et al. Nell-1-induced bone regeneration in calvarial defects. Am. J. Pathol. 2006, 169, 903-915. [CrossRef] [PubMed]

20. Cowan, C.M.; Cheng, S.; Ting, K.; Soo, C.; Walder, B.; Wu, B.; Kuroda, S.; Zhang, X. Nell-1 induced bone formation within the distracted intermaxillary suture. Bone 2006, 38, 48-58. [CrossRef]

21. Cowan, C.M.; Jiang, X.; Hsu, T.; Soo, C.; Zhang, B.; Wang, J.Z.; Kuroda, S.; Wu, B.; Zhang, Z.; Zhang, X.; et al. Synergistic effects of Nell-1 and BMP-2 on the osteogenic differentiation of myoblasts. J. Bone Miner. Res. 2007, 22, 918-930. [CrossRef]

22. Lu, S.S.; Zhang, X.; Soo, C.; Hsu, T.; Napoli, A.; Aghaloo, T.; Wu, B.M.; Tsou, P.; Ting, K.; Wang, J.C. The osteoinductive properties of Nell-1 in a rat spinal fusion model. Spine J. 2007, 7, 50-60. [CrossRef] [PubMed]

23. Siu, R.K.; Lu, S.S.; Li, W.; Whang, J.; McNeill, G.; Zhang, X.; Wu, B.M.; Turner, A.S.; Seim, H.B., 3rd; Hoang, P.; et al. Nell-1 protein promotes bone formation in a sheep spinal fusion model. Tissue Eng. Part. A 2011, 17, 1123-1135. [CrossRef] [PubMed]

24. Pang, S.; Shen, J.; Liu, Y.; Chen, F.; Zheng, Z.; James, A.W.; Hsu, C.Y.; Zhang, H.; Lee, K.S.; Wang, C.; et al. Proliferation and osteogenic differentiation of mesenchymal stem cells induced by a short isoform of NELL-1. Stem Cells 2015, 33, 904-915. [CrossRef]

25. Zhang, X.; Péault, B.; Chen, W.; Li, W.; Corselli, M.; James, A.W.; Lee, M.; Siu, R.K.; Shen, P.; Zheng, Z.; et al. The Nell-1 growth factor stimulates bone formation by purified human perivascular cells. Tissue Eng. Part. A 2011, 17, 2497-2509. [CrossRef] [PubMed]

26. James, A.W.; Shen, J.; Zhang, X.; Asatrian, G.; Goyal, R.; Kwak, J.H.; Jiang, L.; Bengs, B.; Culiat, C.T.; Turner, A.S.; et al. NELL-1 in the treatment of osteoporotic bone loss. Nat. Commun. 2015, 6, 7362. [CrossRef]

27. James, A.W.; Zara, J.N.; Corselli, M.; Askarinam, A.; Zhou, A.M.; Hourfar, A.; Nguyen, A.; Megerdichian, S.; Asatrian, G.; Pang, S.; et al. An abundant perivascular source of stem cells for bone tissue engineering. Stem Cells Transl. Med. 2012, 1, 673-684. [CrossRef]

28. Blazquez, C.; Casanova, M.L.; Planas, A.; Gomez Del Pulgar, T.; Villanueva, C.; Fernandez-Acenero, M.J.; Aragones, J.; Huffman, J.W.; Jorcano, J.L.; Guzman, M. Inhibition of tumor angiogenesis by cannabinoids. FASEB J. 2003, 17, 529-531. [CrossRef]

29. Lai, S.L.; Cheah, S.C.; Wong, P.F.; Noor, S.M.; Mustafa, M.R. In vitro and in vivo anti-angiogenic activities of Panduratin, A. PLoS ONE 2012, 7, e38103. [CrossRef] [PubMed]

30. Pratheeshkumar, P.; Budhraja, A.; Son, Y.O.; Wang, X.; Zhang, Z.; Ding, S.; Wang, L.; Hitron, A.; Lee, J.C.; Xu, M.; et al. Quercetin inhibits angiogenesis mediated human prostate tumor growth by targeting VEGFR- 2 regulated AKT/mTOR/P70S6K signaling pathways. PLoS ONE 2012, 7, e47516. [CrossRef]

31. Tsai, C.H.; Chou, M.Y.; Jonas, M.; Tien, Y.T.; Chi, E.Y. A composite graft material containing bone particles and collagen in osteoinduction in mouse. J. Biomed. Mater. Res. 2002, 63, 65-70. [CrossRef] 
32. Wang, C.K.; Ho, M.L.; Wang, G.J.; Chang, J.K.; Chen, C.H.; Fu, Y.C.; Fu, H.H. Controlled-release of rhBMP-2 carriers in the regeneration of osteonecrotic bone. Biomaterials 2009, 30, 4178-4186. [CrossRef] [PubMed]

33. Pan, H.C.; Lee, S.; Ting, K.; Shen, J.; Wang, C.; Nguyen, A.; Berthiaume, E.A.; Zara, J.N.; Turner, A.S.; Seim, H.B., III; et al. Cyst-like osteolytic formations in recombinant human bone morphogenetic protein-2 (rhBMP-2) augmented sheep spinal fusion. Am. J. Path. 2017, 187, 1485-1495. [CrossRef] [PubMed]

34. Grosso, A.; Burger, M.G.; Lunger, A.; Schaefer, D.J.; Banfi, A.; Di Maggio, N. It Takes Two to Tango: Coupling of Angiogenesis and Osteogenesis for Bone Regeneration. Front. Bioeng. Biotechnol. 2017, 5, 68. [CrossRef]

35. Hankenson, K.D.; Dishowitz, M.; Gray, C.; Schenker, M. Angiogenesis in bone regeneration. Injury 2011, 42, 556-561. [CrossRef] [PubMed]

36. Kaushik, A.P.; Das, A.; Cui, Q. Osteonecrosis of the femoral head: An update in year 2012. World J. Orthop. 2012, 3, 49-57. [CrossRef]

37. Malizos, K.N.; Quarles, L.D.; Seaber, A.V.; Rizk, W.S.; Urbaniak, J.R. An experimental canine model of osteonecrosis: Characterization of the repair process. J. Orthop. Res. 1993, 11, 350-357. [CrossRef]

38. Kim, H.K.; Su, P.H. Development of flattening and apparent fragmentation following ischemic necrosis of the capital femoral epiphysis in a piglet model. JBJS 2002, 84, 1329-1334. [CrossRef]

39. Vélez, R.; Soldado, F.; Hernández, A.; Barber, I.; Aguirre, M. A new preclinical femoral head osteonecrosis model in sheep. Arch. Orthop. Trauma Surg. 2011, 131, 5-9. [CrossRef]

40. Herrmann, M.; Bara, J.J.; Sprecher, C.M.; Menzel, U.; Jalowiec, J.M.; Osinga, R.; Scherberich, A.; Alini, M.; Verrier, S. Pericyte plasticity-Comparative investigation of the angiogenic and multilineage potential of pericytes from different human tissues. Eur. Cell Mater. 2016, 31, 236-249. [CrossRef]

41. Collin-Osdoby, P.; Rothe, L.; Bekker, S.; Anderson, F.; Huang, Y.; Osdoby, P. Basic fibroblast growth factor stimulates osteoclast recruitment, development, and bone pit resorption in association with angiogenesis in vivo on the chick chorioallantoic membrane and activates isolated avian osteoclast resorption in vitro. J. Bone Miner. Res. 2002, 17, 1859-1871. [CrossRef] [PubMed]

42. Globus, R.K.; Patterson-Buckendahl, P.; Gospodarowicz, D. Regulation of bovine bone cell proliferation by fibroblast growth factor and transforming growth factor beta. Endocrinology 1988, 123, 98-105. [CrossRef] [PubMed]

43. Ma, C.; Andre, G.; Edwards, D.; Kim, H.K.W. A rat model of ischemic osteonecrosis for investigating local therapeutics using biomaterials. Acta Biomater. 2021. [CrossRef] [PubMed] 